\title{
LA FISCALIZACION DE LAS ACTIVIDADES SUBORDINADAS DE LAS CORPORACIONES LOCALES
}

352.95

por

\section{Alvaro Alvarez-Gendín}

Doctor en Derecho. Diplomado en Administración local

SUMARIO: I. FISCALIZACION: CLASES.-II. LA FISCALIZACION ADMINISTRATIVA. - III. LA FISCALIZACION ECONOMICO-FINANCIERA: ALGUNOS PROBLEMAS QUE PLANTEA.-IV. LAS INTERVENCIONES DELEGADAS.

\section{FISCALIZACION: CLASES}

La relación del Estado con los demás entes en él encuadrados es diferente según el mayor o menor grado de dependencia o subordinación entre éstos y aquél, y puede ir desde la llamada relación de jerarquía hasta el control de propiedad, pasando por la tutela. Estos términos, por otra parte, van íntimamente ligados con los de fiscalización y control, sin que ni siquiera la doctrina se ponga de acuemdo en cuanto a su utilización con un valor único e inequívoco, y mucho menos la legislación.

No obstante, una mayor o menor fiscalización o control ha de ser ejercida por el Estado respecto a las actividades a él sometidas, bien centralizadas o bien descentralizadas. Pero si esta descentralización es de segundo grado, como en el caso que estudiamos, esa fiscalización habrá de ser ejercida, en primer lugar, por 
la entidad de la que depende directamente. Esta es, principalmente, la fiscalización o control que nos interesa aquí; es decir, la ejercida por la Corporación local creadora de servicios dotados de un mayor o menor grado de descentralización (1) sobre tales actividades, sin descartar la que pueda ejercer sobre las mismas el Poder central en el ejercicio de sus funciones.

Nos referimos, principalmente, a una serie de acciones con fines concretos que las Corporaciones locales realizan a través de organismos dotados o no de personalidad - que en unos casos será pública y en otros de carácter privado mercantil-, pero que siempre poseen una diferenciación orgánica, a saber: órganos de gestión, fundaciones públicas, mancomunidades y consorcios, de un lado, y sociedades privadas y mixtas, de otro.

Su fiscalización, por las Corporaciones locales creadoras o promotoras, es el objeto de nuestra atención.

Ahora bien, la fiscalización puede ser de varias clases (2):

a) Política, administrativa y jurisdiccional, según el órgano de que dimane.

b) Jurídica y de oportunidad, según el mayor o menor grado a que aspire, examinando únicamente la legalidad del acto o bien intentando investigar sus móviles o intenciones.

c) Administrativa y económico-financiera, en razón a la materia; y dentro de la primera cabe distinguir, como veremos, la jurídico-administrativa y la jurídico-económica.

d) Interna y externa, según el punto de vista desde donde se ejercite.

e) Preventiva y represiva, de acuerdo con el fin que persiga de evitación o sanción de la infracción.

Vamos a referirnos, por separado, a cada una de las dos clases de fiscalización, administrativa y económico-financiera.

(1) En algún caso ni siquiera se podrá hablar de «descentralización» en sentido técnico; es decir, tal como lo entiende la doctrina, ya que para ello es necesario que surja una nueva personalidad jurídica, y no siempre ocurre así, verbigracia el órgano de gestión. Por ello, aunque nosotros usamos aqui este término en sentido lato, hemos preferido utilizar en el título de este trabajo el de «subordinación" por considerarlo más comprensivo, si bien sea ajeno al de jerarquización.

(2) Ver Garcfa-TreviJano, Tratado de Derecho administrativo, tomo II, páginas 446 y sigs. 


\section{LA FISCALIZACION ADMINISTRATIVA}

La fiscalización administrativa por medio de autorizaciones previas o de aprobaciones a posteriori, y también un tipo especial de fiscalización jurídico-administrativa y jurídico-económica por vía de recurso, pues aquí no hay distinción de materia. Aun cuando exista un procedimiento especial que nuestro Derecho denomina económico-administrativo, pero cuyo conocimiento corresponde al Poder central.

En cuanto a los diversos tipos de entes o personas descentralizadas creadas por las Corporaciones locales, es indudable que las que podemos incluir dentro de la gestión descentralizada de Derecho privado, como es la empresa privada y la empresa mixta, quedan fuera de este tipo de fiscalización de orden jurídico-administrativo, ya que su Estatuto, como es sabido, corresponde al Derecho mercantil y, por tanto, su fiscalización es únicamente jurisdiccional y encomendada a los Tribunales ordinarios.

El control administrativo no existe en principio para este tipo de actividad, es un mero control de propiedad o participación ejercido a través de los votos que la Corporación tenga en los órganos de gobierno de la sociedad (Junta general y Consejo de Administración, si es anónima); cuyo capital puede ser exclusivo, como en el caso de la sociedad privada municipal o provincial; o no, si de empresa mixta se trata; pero siempre mayoritario —entendemos nosotros (3)-, pues en otro caso no tendría el carácter de empresa pública. Sin embargo, comentaremos como caso curioso el hecho de que, tratándose de empresas mixtas municipales o provinciales, el Reglamento de Servicios, en su artículo 106, admite un menor número de votos de la Corporación en los órganos de gobierno de la sociedad que el que resulte de la proporción de su participación capitalista.

No obstante, lo normal es que tratándose de empresas que gestionen servicios públicos no estén exentas estatutariamente de un cierto control administrativo, de aprobación de ciertos actos o confirmación de cargos de los adminitradores, etc., por parte de la Entidad local creadora del servicio. (Ver, con respecto al Secretario

(3) Hay que reconocer, no obstante, que el Reglamento de Servicios no lo expresa claramente así, solamente exige la previa municipalización (artículo 104), pero quizá pudiera deducirse de su contexto. 
e Interventor, lo dispuesto en los artículos $131, b$ ), y 149, b), del Reglamento de Funcionarios, los cuales no tienen carácter taxativo).

En el caso de actividades de Derecho público ejercidas a través de fórmulas asociativas, como la mancomunidad y el consorcio, ocurre algo parecido. Por ser personas jurídicas (4) no existe control de la misma clase por parte de las Entidades locales patrocinadoras: sus actos causan estado, siendo fiscalizables únicamente en vía contencioso-administrativa. También, sin embargo, puede existir un cierto control administrativo previsto en sus Estatutos, mayor o menor según los casos, porque en esto - como se sabenada previene la Ley; y, naturalmente, compartido.

Si la fórmula empleada es la fundación pública de servicio, con personalidad jurídica, ocurre cosa semejante a lo expuesto anteriormente, únicamente que el control será ejercido por una sola Corporación local, lo cual es una ventaja. En este supuesto admitimos, sin embargo, la posibilidad de que la Corporación fundadora se reserve el establecimiento en los Estatutos de un recurso de alzada ante ella, como expresión de su acción fiscalizadora, en base a lo dispuesto en el artículo 87 del Reglamento de Servicios.

La cuestión más dificultosa se presenta precisamente en la gestión directa con órgano especial de administración. Es entonces cuando entra la duda de si estamos ante una relación de jerarquía

(4) Respecto a la personalidad jurídica de los consorcios locales no hay duda, según se desprende del artículo 37, 2, del Reglamento de Servicios. Y en cuanto a que esa personalidad es de carácter público, tampoco existe reparo serio que oponer, pues al ser públicas las Entidades que lo integran "para el cumplimiento de sus fines» y no hacerse excepción, parece lógico que así sea. Lo que sí se discute es su cualidad de ente local, pero autores como Martín Mateo (Los Consorcios locales, Madrid, Instituto de Estudios de Administración Local, 1970, pág. 58; y en "Un nuevo tipo de empresas: los Consorcios locales», comunicación al XIII Congreso Interamericano de Municipios, Colombia, julio de 1970) y MARTiNez LOPEZ MuÑIz (Los Consorcios en el Derecho español, Madrid, Instituto de Estudios de Administración Local, 1974, págs. 404 y sigs.), afirman que lo característico en ellos no es ser una forma de prestación de los servicios locales, sino el ser una Entidad local. Las bases 22 y 66 del Proyecto de Ley enviado a las Cortes en enero de 1972 los configuraban como tales entes locales. Y el actual Proyecto de Ley, si bien no dice nada al respecto al hablar de ellos en su base 38, 4, sí parece reconocerles este carácter en la base 1., 5 , si bien diferenciándolos de las Entidades territoriales y corporativas, como es lógico. Por otra parte, a efectos fiscales tienen reconocida dicha equiparación por el Decreto-ley de 12 de noviembre de 1970, en cuyo preámbulo se lee: aLa preterición legal que, en materia de exenciones, se observa con respecto a los consorcios, solamente denuncia un olvido de expresión o enumeración del ordenamiento vigente en su proyección subjetiva, pues si los consorcios sustituyen en su cometido a la acción de los entes consorciados, lógicamente deben gozar del mismo trato fiscal que éstos, siempre que las Entidades públicas de diferente orden concertadas (serán consorciadas) en ellos con las Corporaciones locales disfruten de idéntico régimen fiscal». 
o bien de tutela; porque si bien es un ente sin personalidad, no cabe duda de que sus órganos están en cierto modo diferenciados, aunque no en su totalidad, como veremos.

Por una parte existe un Consejo de administración, un Presidente del mismo y, además, un Gerente como órgano ejecutivo. Se trata de un caso de delegación autorizada por la ley, o bien de desconcentración previsto en ella, según la opinión que se comparta (5).

De ahí que, en caso de recurso administrativo y ante tal diversidad de órganos, ¿cuál de ellos es competente y ante cuál debe interponerse? Y en su caso, ¿existiría o no la alzada?

En realidad, esta cuestión viene resuelta por el Reglamento de Servicios de las Corporacciones locales (artículo 72), en el que se precisa que los acuerdos del Consejo de administración "serán recurribles en alzada ante la Corporación", de lo cual se deduce también que es dicho Consejo el competente para conocer y ante quien debe interponerse (6). Como se ve, la legislación de Régimen local es más explícita en este punto que la legislación general en donde queda sin resolver la cuestión.

No obstante, como el Gerente de estos servicios tiene facultades que le son propias, pudiera ocurrir que alguno de sus actos fuese recurrible, en cuyo caso la alzada habría que plantearla - de no establecerse otra cosa en los Estatutos- ante el Consejo de administración, que actuaría como órgano delegado de la Corporación, quedando ya expedita la vía ante los Tribunales contencioso-administrativos por aplicación del principio contenido en el artículo 122 de la Ley de Procedimiento administrativo (reformado por Ley de 2 de diciembre de 1963) - aplicable, como se sabe, subsidiariamente a las Corporaciones locales-, que no admite más que un solo recurso de alzada (7).

(5) A tal efecto citamos la opinión de ORTIz Dfaz en La descentralización territorial en la Administración local (págs. 111-114), que califica el fenómeno de «desconcentración por servicios, en cierto modo análogo -servata distancia- al de la denominada descentralización por servicios, si bien producida, como es lógico, dentro de una misma persona juridica pública y que conlleva una desconcentración de la administración presupuestaria y patrimonial del servicion.

(6) Ver artículo 156 del Reglamento del órgano de gestión de los Servicios asistenciales sanitarios de la Diputación Provincial de Asturias.

(7) Ver aplicación de este principio a los organismos autónomos en Guaita, «Organismos autónomos y recurso de alzada» (separata revista Documentación Administrativa, núm. 104). 
En materia económico-administrativa, la regla general es que el recurso de reposición es potestativo (artículo 380 de la Ley de Régimen local), por lo que habrá que convenir que, en estos casos, tampoco será necesario el recurso de alzada previsto anteriormente, quedando expedita la vía ante los Tribunales económico-administrativos, ya que, además, estos actos no suelen adoptar la forma de acuerdos del Consejo, sino de resoluciones de la Gerencia.

En el Reglamento del órgano de gestión de los Servicios asistenciales sanitarios de la Diputación de Asturias (artículo 154), por ejemplo, se prevé la posibilidad de reclamar ante la Gerencia contra la calificación socio-económica de los pacientes que realice el Jefe del Departamento de Gestoría (oficina liquidadora de las tasas), contra cuya resolución -entendemos nosotros- queda abierta la anterior vía ante los Tribunales de la Hacienda pública y, en su caso, ante los contencioso-administrativos por las razones ya expuestas.

Las providencias de apremio, estimamos deben quedar reservadas a los Presidentes de las Corporaciones, por considerar que no debe ser materia delegable; no obstante, nuestro Derecho positivo nada determina acerca del particular.

En materia de aprobación de Reglamentos y Ordenanzas generales habrá que estar a lo que dispongan los propios Estatutos; pero en caso de silencio consideramos que, tanto en esto como en materia de actos de disposición del patrimonio, habrá de interpretarse como reservada a la Corporación; es decir, restrictivamente, la delegación.

La contratación que se derive de ejecución del Presupuesto especial, no de los extraordinarios, se entenderá, por el contrario, como delegada en el Consejo o en el Gerente según la cuantía que determina para la Corporación y el Presidente el Reglamento de Contratación de las Corporaciones locales.

Las facultades en materia de personal deben entenderse delegadas también. Sin embargo, aquí surge una cuestión delicada, como en general en todo lo que se refiere a la fiscalización administrativa o de cumplimiento de los acuerdos de la Corporación por lo que respecta al Secretario de la misma -o persona en quien delegue-, que según la Ley es el órgano a quien corresponde dicha fiscalización, así como la jefatura de todo el personal. Entendemos que, en este punto, su función debe de quedar garantizada en todo momento para que pueda ser cumplida sin menoscabo alguno, es- 
tableciendo sus Estatutos, ya que la normativa vigente no lo hace, el mecanismo adecuado para que pueda ser salvaguardia de lo dispuesto en la Ley, en los Reglamentos y en los acuerdos de la Corporación, que no en vano tienen rango superior a los del Consejo, por lo que deben ser respetados.

Por otra parte - si se considera que estamos ante un caso de delegación de funciones-, como entendemos que la competencia entre delegante y delegado es alternativa, siempre cabe a la Corporación asumir en un determinado momento cualquier función y, por ser esencialmente revocable -como los mandatos-, avocarla o bien revocar cualquier acuerdo o resolución de los distintos órganos del ente, que contravenga o lesione sus intereses.

\section{LA FISCALIZACION ECONOMICO-FINANCIERA: ALGUNOS PROBLEMAS QUE PLANTEA}

A los fines exclusivos de este trabajo, por fiscalización económico-financiera entendemos aquella que han de llevar a cabo las Corporaciones fundacionales sobre la actividad de este carácter realizada por los entes $u$ órganos descentralizados o subordinados - por utilizar una terminología más amplia- de la Administración local, sin olvidar la que corresponde ejercer a las respectivas autoridades de la Administración central en virtud de las atribuciones propias que les confiere la legislación vigente. Pero a esta última no nos referimos aquí; y además, la estudiada por nosotros la consideramos ejercida por los órganos normales de gestión y fiscalización económica, es decir, por la Intervención financiera de la propia Corporación.

También es obvio decir que la fiscalización que puede ejercerse con respecto a aquellas actividades de servicio público o no, pero que generalmente tienen un fondo industrial o mercantil y, por tanto, suelen adoptar la forma de empresa privada o mixta, precisamente por exorbitar la esfera del Derecho público, quedan un poco al margen de este tipo de controles (8), teniendo más bien - como ya hemos dicho al hablar del aspecto administrativo- un carácter patrimonial o de propiedad a través de su participación

(8) La contabilidad es privada y sometida a los preceptos del Código de comercio. 
en el capital de la misma $(9,10)$. No obstante, de alguna manera pueden existir, y de hecho son frecuentes en los Estatutos de estas empresas, facultades de tutela económica y financiera por parte de las Administraciones locales.

Así, por ejemplo, es normal que las tarifas que han de regir dichos servicios o actividades hayan de ser aprobadas por la Corporación y que la censura de cuentas y balances se encomiende igualmente a ella, debidamente asesorada por el Interventor (11), independientemente de la que corresponde hacer a los accionistas designados por la Junta general, en cumplimiento de los preceptos mercantiles aplicables, si se tratase de empresa mixta.

También es frecuente que el Interventor de la Corporación forme parte de sus órganos de gobierno, pero ello lo interpretamos como un modo de dar cumplimiento a lo establecido en la Regla 8. ${ }^{\mathrm{a}}$ de la Instrucción de Contabilidad, aneja al Reglamento de Haciendades locales, cuando dice: «El Interventor ejercerá la asesoría económica y financiera de la Corporación y de los Servicios municipalizados o provincializados y empresas de economía mixta».

En algunos casos se va incluso más lejos, y citamos para ello lo previsto en el artículo 32 del proyecto de reforma de los Estatutos de la Empresa Municipal de Transportes de Madrid, en el que se dice textualmente: «El Secretario general y el Interventor de Fondos municipales actuarán en la empresa con las facultades

(9) Ciertamente éste es bastante escaso en la sociedad privada municipal o provincial, sólo de un tercio por paradoja; en cambio, en proporción al capital - también menor en la mixta. En este caso, la mitad serán técnicos, nosotros interpretamos funcionarios (ver artículos 93, 106 y 107 del Reglamento de Servicios de las Corporaciones locales).

(10) Lo que existe es un control remoto sobre estas actividades y, en general, sobre todas las municipales y provinciales ejercido por el Servicio Nacional de Inspección y Asesoramiento de las Corporaciones Locales, según facultad concedida por el artículo 355 de la Ley de Régimen local, y encomendado a la Comisión Central de Cuentas de dicho organismo, en el artículo 2. del Decreto de 28 de mayo de 1954, cuya competencia se extiende hoy, como es sabido (Decreto de 26 de julio de 1956), a toda clase de Corporaciones locales. Lo cual, si se ejerce con plena efectividad, tiene importancia además a fin de poder conocer en su conjunto la incidencia de estos servicios dentro del sector público local, de igual forma que lo establecido para las empresas paraestatales a efectos de contabilidad nacional. Lo que, por otra parte, no creemos disminuya en nada la autonomía y agilidad de las empresas municipales y provinciales.

La Orden de 21 de febrero de 1962 asigna a dicho organismo del Ministerio de la Gobernación la facultad de realizar la estadística de los mencionados servicios municipalizados, pero no incluye las formas mercantiles de prestación, lo que acaso sería conveniente por las razones expuestas.

(11) Sin duda en cumplimiento de lo estipulado en el artículo $149, b$ ), del Reglamento de Funcionarios, que no es taxativo, como ya hemos visto. 
y obligaciones propias de sus respectivos cargos, determinadas en el Reglamento de Funcionarios de la Administración local» (12).

Tratándose de fórmulas asociativas de Derecho público (mancomunidades y consorcios), al ser personas jurídicas públicas el control es ejercido en la misma forma que sobre las Corporaciones locales, aplicándose en este punto la legislación general del Régimen local (13), si bien lógicamente adaptado a su peculiar forma de ser, por lo que el control externo será únicamente de primer grado ejercido por los correspondientes órganos estatales. De ahí que la aprobación de ordenanzas fiscales, presupuestos ordinarios y extraordinarios, cuentas generales, etc., se realice en la misma forma. Lógicamente los recursos financieros serán otros, ya se establece para las mancomunidades en el Reglamento de Población y Demarcación territorial (artículo 62,e) que deben ser determinados en sus Estatutos, así como para los consorcios en el artículo 39 del Reglamento de Servicios de las Corporaciones locales las particularidades de su régimen.

El control por parte de las Corporaciones integrantes se ejercerá, por tanto, del mismo modo que para las formas asociativas de Derecho privado, a través de sus participaciones en los órganos de gobierno. Se trata, pues, de un control de propiedad o participación.

En cuanto a los órganos de control interno se establece en el artículo 64, núm. 3, del mencionado Reglamento de Población y Demarcación territorial, para las mancomunidades, que los cargos de «Secretario o Secretario-Contador, así como los de Interventor y Depositario de fondos, si existieren, habrán de ser ejercidos por funcionarios de los respectivos Cuerpos nacionales". (En parecidos términos, para los consorcios, los artículos 131 y 149 del Reglamento de Funcionarios referidos a los Secretarios e Interventores).

(12) En el Derecho municipal alemán es preceptiva la censura de cuentas por parte de la Corporación en toda clase de explotaciones y empresas municipales, con independencia de su forma jurídica, según se estableció ya en la disposición dictada el 6 de octubre de 1931, así como la fiscalización propia por parte de la oficina interventora de la Entidad local de la que dependa. Consultar GöNnENWEIN, Derecho municipal alemán, págs. 704 y 705.

(13) La contabilidad, por tanto, habrá de someterse a la Instrucción aneja al Reglamento de Haciendas locales, con presupuesto especial para las mancomunidades, según se dispone en el artículo 704, 2, de la Ley de Régimen local; si bien nosotros estimamos que, tratándose de servicios con personalidad jurídica pública, su presupuesto de funcionamiento debiera tener carácter de ordinario de la Entidad, y así lo consideramos para los consorcios, puesto que no existe precepto en contrario. Ver, en relación con estas cuestiones, lo dispuesto en el número 3, D), de la Orden de 10 de agosto de 1965 sobre formación de presupuestos. 
Entendemos nosotros que, existir, debieran existir siempre; lo que ocurre es que, de acuerdo con su importancia económica y financiera, deberían ser ocupados dichos cargos por los de las Corporaciones integrantes o con mayor aportación - función que, por otra parte, podría ser delegable-, que mereciesen tal designación por parte de la Junta de gobierno o Comisión gestora respectiva, o bien por designación de la Dirección General de Administración Lccal en concurso ordinario del respectivo Cuerpo, según los casos.

En cuanto a los actos económicos, y en general los administrativos, causan estado en esta clase de personas públicas y precisamente en razón de ello. En el caso de la fundación pública unipersonal podemos repetir lo dicho para las anteriores formas por lo que se refiere al control económico estatal, con las variantes naturales; en cuanto al ejercido por la Corporación de quien dependa, no cabe duda que será también de Derecho público (14), pero estatutariamente habría que determinarlo, al menos en su intensidad, como se desprende del artículo 87 del Reglamento de Servicios de las Corporaciones locales. Por eso, en este caso, creemos que las facultades interventoras, así como las que correspondan al Secretario y al Depositario en sus respectivos cometidos, debieran ser ejercidas por los de la Corporación o funcionarios en quien ellos deleguen, si la importancia del caso lo requiere, todos ellos pertenecientes a los respectivos Cuerpos nacionales.

También es normal, como en las anteriores formas, una censura de cuentas o aprobación de tarifas establecidas en los Estatutos.

Como siempre, la dificultad mayor se encuentra en la gestión directa con órgano especial de gestión, por ser, como sabemos, una fórmula híbrida de descentralización.

El régimen económico de estos organismos viene regulado por los artículos 76 y siguientes del Reglamento de Servicios de las Corporaciones locales. En el primero de ellos se establece que «el órgano especial tendrá presupuesto independiente (15), que será aproba-

(14) Asimismo la contabilidad deberá ser pública, derivada de un presupuesto especial o más bien ordinario - según el criterio-; aunque nuestra actual legislación no parece obligar a ello, por lo que muchos son partidarios de una simple contabilización privada, pero estimamos que cuando la importancia del caso lo requiera así debiera exigirse. Ver norma 4.2.4, Orden de 10 de agcsto de 1965.

(15) Prescripición que ya viene establecida por precepto legal, ver artículo 174 de la Ley de Régimen local. Este tipo de presupuestos sí que no hay ningún incon- 
do anualmente por la Corporación, con arreglo a los preceptos aplicables a los Presupuestos ordinarios", cuya gestión se encomienda al Consejo de administración (artículo 72), así como la formación del proyecto, correspondiendo la del anteproyecto al Gerente (artículo 79), a quien se configura también como Ordenador de pagos (artículo 75, d). «La contabilidad de los servicios prestados en régimen de gestión directa con órgano especial se llevará por la Intervención de Fondos de la Corporación, con independencia de la general (16).

Las cuentas anuales se sujetarán a las normas establecidas para las Entidades lccales y deberá rendirlas el Consejo de administración y aprobarlas el Servicio Nacional de Inspección y Asesoramiento, previo informe de la Corporación.

Los balances y liquidaciones anuales se publicarán en el Boletín Oficial de la Provincia (artículo 80).

No se dice nada respecto a la custodia de fondos, pero habrá de interpretarse por extensión que corresponde al Depositario (artículo 768-1 de Ley de Régimen local).

También silencia el Reglamento de Servicios el contenido y procedimiento a seguir para la aprobación de las ordenanzas fiscales, por lo que en este aspecto habrá de atenerse a lo dispuesto en las normas generales de ordenación de exacciones, una vez hecha la propuesta formal por el Consejo de administración.

Otro defecto que se observa en el Reglamento de Servicios es no haber contado con el concepto de amortización, pero quizá ello se deba a que está previsto que las inversiones corran a cargo del Presupuesto de la Corporación, por lo que entonces sobra aquella idea. No obstante, creemos que si de veras esta forma de gestión ha de estar presidida por criterios empresariales, nunca debió olvidarse la existencia de un fondo de amortización.

veniente en configurarlos como especiales, aun cuando no se diga expresamente, por no tener el órgano especial personalidad jurídica. Ver a este respecto la norma 4.2.1, Orden citada en la nota anterior.

(16) La desafortunada redacción de este precepto ha hecho comentar a algunos autores, entre ellos ALBI, que al Interventor le competía únicamente -con respecto a estos organismos- dirigir la contabilidad. Pero aparte las disposiciones generales de la Ley en este sentido, no cabe duda que el autor del Reglamento de Servicios se está refiriendo también a la función fiscalizadora, pcrque si no para qué encomendar esta misión al Interventor, podría realizarla cualquier otro funcionario con preparación suficiente. En todo caso, el precepto fue redactado para reafirmar la independencia del presupuesto especial, pero en nada merma las funciones interventoras con respecto a cualquier acto de la Corporación con trascendencia económica, y no hay que olvidar que el órgano de gestión es Corporación también. 
El resto de los preceptos está dedicado a determinar los ingresos y gastos que han de integrar dichos presupuestos, así como al destino que ha de darse a los beneficios del servicio, si los hubiese, mediante la creación de un fondo de reserva o la atención de necesidades generales de la Corporación.

Es éste un problema interesante, al menos teóricamente, que merece nos detengamos en él ya que, a nuestro modo de ver, establece en este punto un sistema doble de contabilidad -público y privado- necesario a todas luces para la determinación de los beneficios del servicio.

Efectivamente, en el artículo 80,3, se dice textualmente que «los balances y liquidaciones..., etc., etc.", y en el artículo 81 del mismo cuerpo reglamentario se dispone que "los beneficios que se obtuvieren...». Se habla también en el artículo 83 de la «cuenta de Pérdidas y Ganancias», etc.

La terminología utilizada recuerda, como puede observarse, la que suele seguirse en la contabilidad privada, y no cabe duda que para la determinación del beneficio, en el sentido que este término se utiliza en la esfera económico-privada — que no coincide en absoluto con el superávit presupuestario-, se hace imprescindible una contabilidad por partida doble, lo cual daría como resultado la determinación de éste y la fijación de un balance de empresa, al que también se alude en dichos preceptos. Mas como, por otra par. te, en el régimen económico establecido en el Reglamento de Servicios para el órgano de gestión no se descarta, sino todo lo contrario - como ya hemos visto también-, el sometimiento a un presupuesto y a todo un sistema de contabilización pública, de ahí que parezca deducirse la necesidad de llevar dos contabilidades; que nada tiene que ver, por supuesto, con la duplicidad fraudulenta que persigue la ley fiscal, sino que, como todo parece indicar, viene impuesta del propio ordenamiento jurídico, a los únicos y exclusivos fines que acabamos de exponer.

Ahora bien, una coexistencia pareja de contabilidad plantea el problema de la prioridad de una de ellas. A nuestro modo de ver, no hay primacía. Cada una persigue una finalidad distinta; la pública, la garantía en el manejo de fondos que pertenecen a la comunidad; la privada, la determinación con criterios privatísticos y auténticamente empresariales de las utilizadas que la ley permite obtener de los servicios municipalizados o provincializados; es decir, del resultado de la gestión con un criterio lucrativo, aunque 
ése no sea su fin primordial. No son, pues, razones de agilización -como ocurre con las formas privadas de prestación de servicios públicos (empresa privada municipal o provincial y empresa mixta, en el caso de los locales)-, por lo que de primar alguna de dichas contabilidades, habría que inclinarse por la que mayores garantías ofrezca en cuanto al manejo de los fondos públicos.

Entrando en el examen de la regulación que hace el Reglamento de Servicios, vemos que los beneficios a que hace referencia el artículo 81 se aplicarán:

a) A fondo de reserva, en el porcentaje del sobrante, que se determinará al implantar la municipalización o provincialización, sin que sea inferior al 20 por 100; y

b) A las necesidades generales de la Corporación, en el resto que resultare.

El fondo de reserva equivaldrá al 50 por 100 del capital inicial del organismo, y deberá ser repuesto si decreciere de esa cuantía.

Dicho fondo será objeto de contabilidad separada de la ordinaria de la Corporación, y se integrará en cuenta especial de la géneral del órgano especial.

El fondo de reserva constituirá una disponibilidad para hacer frente al saldo deudor de la cuenta de Pérdidas y Ganancias, o gastos extraordinarios que se originaren por circunstancias anormales, sin perjuicio de destinar hasta el límite del 60 por 100 del mismo, cuando hubiere llegado al máximo fijado por el artículo anterior, a garantizar la emisión de Deuda con destino a la ampliación o renovación de instalaciones.

No se podrá disponer del fondo de reserva sino en virtud de propuesta del Consejo de administración, adoptada por mayoría de los dos tercios del número legal de sus miembros y aprobada por la Corporación con idéntico quorum, y las operaciones que se efectuaren con cargo al mismo requerirán presupuestos extraordinarios o habilitaciones o suplementos en el presupuesto especial (artículos 82-84 del Reglamento de Servicios).

La lectura de estos preceptos aún suscita algunos comentarios. En primer lugar, cuando alude a una contabilidad separada y a una cuenta especial de la del órgano de gestión, ¿estará refiriéndose a la contabilización del fondo de reserva en valores independientes y auxiliares del presupuesto? Estimamos que sí. 
Por otra parte, hay que observar cómo el fondo de reserva constituye una excepción en cuanto a su aplicación al principio establecido en el artículo 78 de que el presupuesto del órgano de gestión es un presupuesto de mantenimiento, excepción que ya se puede contemplar en el propio precepto a que acabamos de referirnos. Todo ello está muy de acuerdo con los criterios empresariales que, en cierto modo, presiden también esta forma de prestación de los servicios públicos locales.

Como contrapartida, el quorum establecido para su disposición no puede ser más exigente, incluso supera al del artículo 303 de la Ley de Régimen local, que es el que rige en los actos más trascendentales de la vida de las Corporaciones locales.

Todo ello hace pensar que el Reglamento de Servicios ha regulado un sistema teóricamente perfecto, aunque en su redacción no sea muy explícito. Sin embargo, en la práctica el sistema es complicado y hasta discutible, ya que hay quien opina incluso que, deducida de los beneficios la aportación al fondo de reserva, sólo debe pasar al Presupuesto ordinario de la Corporación, como máximo, la aportación de éste al especial. Por ello es frecuente que, de haberlo, se identifique beneficio con superávit presupuestario y sea éste el que revierta en todo o en parte al ordinario o a los especiales de otros servicios.

Esta es la consecuencia a que, a pesar de estar reglamentariamente dispuesto, se llega ciertamente por razones de orden pragmático en caso de existir unas utilidades que, por otra parte, no siempre pueden producirse, dado que se trata de la prestación de servicios públicos no siempre lucrativos, aunque sean municipalizados o provincializados. Pero esto ya sería otra cuestión a debatir.

Entremos ya, por tanto, de lleno en la cuestión de la fiscalización económica. Independientemente de la fiscalización que corresponde a los órganos estatales sobre los locales, no cabe duda que al existir una diferenciación de órganos con respecto a los de la Corporación surge también la necesidad de una fiscalización de segundo grado, aun cuando no exista una personalidad jurídica di-. ferente. No es que se trate de un control externo en realidad, por la razón acabada de exponer, pero sí se le parece bastante.

De una parte, corresponde por precepto al Interventor la fiscalización económico-financiera de los ingresos y gastos pertenecientes a todos los presupuestos de la Corporación, tanto ordina- 
rios como extraordinarios o especiales. De otra, la existencia de dos escalones en la organización administrativa y económica dificulta a veces la cuestión.

En el plano legislativo debiera expresarse en primer lugar claramente que al Interventor, o al funcionario en quien delegue, se le habrá de convocar a todas las sesiones del Consejo de administración y de las Comisiones informativas, a fin de que pueda ejercer debidamente su función, con las mismas prerrogativas que le corresponden respecto a los demás órganos colegiados de la Corporación. Es cierto que los Estatutos de estos organismos contienen en la mayoría de los casos preceptos semejantes, pero entendemos debe ser una norma de carácter general la que lo disponga.

Por otra parte, y puesto que en esta clase de presupuestos especiales, tanto el anteproyecto como el proyecto se confeccionan por sus órganos naturales (Gerente y Consejo, respectivamente), sería conveniente expresar también la necesidad de contar con el asesoramiento técnico del Interventor o su delegado. A esto podrá objetarse que dicho funcionario ya informará cuando el presupuesto pase a la Corporación; pero su falta de asistencia desde el primer momento podría acarrear retrasos y retrocesos innecesarios. No se nos escapa que así ocurrirá también en muchos casos de facto, pero es conveniente que se establezca preceptivamente.

El resto de los documentos importantes de la gestión económica, es claro que su aprobación será ajena también al órgano de gestión; ya lo hemos visto para las cuentas anuales (general, de administración del patrimonio y de valores independientes y auxiliares del Presupuesto) (17). Y así lo estimamos también para las ordenanzas fiscales, las cuales - una vez aprobadas por la Corporación a propuesta del Consejo, debidamente asesorado también

(17). Sin embargo, con respecto a éstas surgen dudas, dada la defectuosa redacción del mencionado artículo 80 del Reglamento de Servicios, en cuanto al órgano administrativo, a quien ordinariamente corresponde su aprobación provisional, que es la Corporación, ya que en dicho precepto solamente se le confiere su informe. Pero estimamos que ello se debe únicamente a la aludida falta de fortuna en su confección, debiendo prevalecer el criterio legal, que es la norma general a que se remite el Reglamento. La rendición, por otro lado, corresponde al Consejo y no al Ordenador de pagos.

¿Y en lo referente a la liquidación del presupuesto, que no es más que una parte de la cuenta general? En esto sí que, ante el silencio reglamentario, debe seguirse la. norma general de confección por el Interventor y aprobación por el órgano corporativo competente, según los casos, si bien estimamos que su resultado debe ser conocido por el Consejo de administración. Respecto a las trimestrales de caudales que rinde el Depositario, no vemos razón para que no se siga la norma general, a pesar del silencio del precepto comentado. 
por el Interventor o su delegado- seguirán el procedimiento ordinario.

Con referencia a la ordenación del gasto, es claro que el órgano de gestión tiene esta facultad delegada de la Corporación. De ahí que se plantee el problema de la atribución de funciones entre los distintos órganos que lo componen ante el silencio reglamentario. Si se sigue el criterio de repartir las competencias de la Corporación y su Presidente en el Consejo de administración y el suyo, dicho criterio es correcto, y éste parece ser el mantenido por la Dirección General de Administración Local en algún caso consultado, siempre, claro está, que se realice el gasto de acuerdo con las formas establecidas en el Reglamento de Contratación de las Corporaciones locales. No obstante, podía haberse seguido, por vía estatutaria, el criterio de reparto de las funciones presidenciales (corporativas y ejecutivas) entre el Presidente del Consejo de administración y el Gerente del órgano de gestión, en cuyo caso la ordenación del gasto correspondería en una cierta medida a este último o bien a los dos, según los casos, y no creemos exista prohibición legal expresa para poder establecerlo así en sus normas fundacionales.

En cuanto a la ordenación de pagos, cosa distinta de lo anterior, como es bien sabido, la opinión de la Dirección General de Administración Local es que debe dividirse entre el Presidente del Consejo y el Gerente, según exista o no consignación expresa en el presupuesto, de acuerdo con lo estipulado en el artículo $75, d$ ), del Reglamento de Servicios. Sin embargo, el término "consignación expresa" no es muy claro, ya que si se refiere a la existencia de una partida presupuestaria ésta deberá producirse siempre o bien. crearse al efecto, y si se quiere expresar algo más concreto, pocas veces ocurrirá esto en la práctica, con lo cual las facultades gerenciales en esta materia serían prácticamente nulas en contra de lo dispuesto en el propio artículo $75, d)(18)$. Pero es que, además, la función de clavero o de custodia de fondos quedaría también di-

(18) En la práctica hay quien va más allá todavía, así en el Reglamento de los Servicios asistenciales sanitarios de la Diputación de Madrid se encomienda la ordenación de pagos - dentro de los límites de su competencia- al Administrador general, especie de Gerente administrativo. Esto quizá sea muestra del recelo que inspiran los Gerentes técnicos en este punto; pues, salvo excepciones, suelen tener, como es natural, poco sentido administrativo y económico, en rázón precisamente de su especial formación y vocación. Es importante en estos casos la independencia de la función cuando la envergadura del gasto así lo exija; ésta quizá ha sido la razón del caso a que nos referimos. 
versificada, y tal cosa ya no es lógica. En cuanto esta última, aparte de corresponder al Gerente, entendemos que al ser propia del Ordenador de pagos - y no delegada - pudiera éste realizar la delegación en un funcionario, por ejemplo en el administrador o en el director administrativo - si existiera esta figura-, sobre todo cuando le sustituyeran. Todo esto, como es natural, depende, claro está, del volumen e importancia de la organización.

\section{LAS INTERVENCIONES DELEGADAS}

Cuestión importante es también la de las intervenciones delegadas. Se observará que siempre nos referimos al Interventor «o funcionario en quien delegue», y es que en esta materia consideramos importante - no por razones de garantía, sino de división de trabajo- descargar al Interventor, cuando el volumen y la complejidad de la organización lo justifiquen, de la tarea de fiscalizar todos y cada uno de los actos de ejecución del presupuesto. En algunos casos bastará con una simple delegación de firma en alguno de los funcionarios a sus órdenes para la formalización de ciertos documentos (mandamientos de pago o de ingreso, o simplemente cartas de pago), pero en otros se requerirá la dedicación constante y permanente de un funcionario que, en este caso, deberá pertenecer al Cuerpo nacional correspondiente.

Esto es lo que ocurre, por ejemplo, con el órgano de gestión de los Servicios asistenciales sanitarios de la Diputación de Asturias, para el cual existe una delegación permanente del Interventor general de la Corporación en favor del Viceinterventor de la misma. La representación en el Consejo, salvo en casos de suplencia, la ostenta, no obstante, el Interventor.

$\mathrm{Y}$ es que, a medida que aumentan los órganos descentralizados dentro de las Corporaciones locales, este tipo de delegaciones se hace imprescindible, aparte que el trabajo en equipo de la intervención económica y financiera vigoriza el ejercicio de su función. Por eso consideramos que esta teoría es extensible a todo tipo de organismos descentralizados (fundaciones públicas, mancomunidades y consorcios) cuando la fiscalización sea ejercida por la propia Intervención de la Corporación creadora del servicio.

En estos casos, de órganos de gestión hipertrofiados, será necesario mantener unos servicios de contabilidad general y de cos- 
tos, gestión de ingresos y caja, etc., cuya dependencia funcional respecto a la Intervención y a la Depositaría de la Corporación, respectivamente, consideramos imprescindible, independientemente de la relación funcionarial existente o de su vinculación o no al órgano de gestión o entidad a través de su Administrador o Gerente (19).

Este es el caso también del órgano de gestión de la Diputación de Asturias, en cuyo Reglamento se previenen normas en este sentido (artículos 62, 63 y 64). La razón es obvia, se trata de salvaguardar la independencia de estos funcionarios en el ejercicio de su misión fiscalizadora o de control. Aún así, a veces, la actuación de los mismos resultará difícil y delicada.

(19) Este criterio es análogo al que se sigue en la Administración central, según. lo dispuesto en el artículo 2. se aprueba el Reglamento del Cuerpo de Intervención y Contabilidad, en el que se dice que a sus funcionarios, "actuando expresamente en cada caso como Delegados del Interventor general de la Administración del Estado, les competen las siguientes funciones, que ejercerán con absoluta independencia de las autoridades cuya gestión fiscalicen...n; dependencia funcional del Ministerio de Hacienda, que ya era mantenida con respecto del personal adscrito a dichas oficinas por los Decretos de 3 de octubre de 1952 y 25 de enero de 1968. 


\section{REVISTA} DE

\section{CRONICAS}


REVL-1975, núm. 188. ALVAREZ-GENDIN Y VALDES-HEVIA, ALVARO. LA FISCALIZACION DE ... REVL-1975, núm. 188. ALVAREZ-GENDIN Y VALDES-HEVIA, ALVARO. LA FISCALIZACION DE ... 